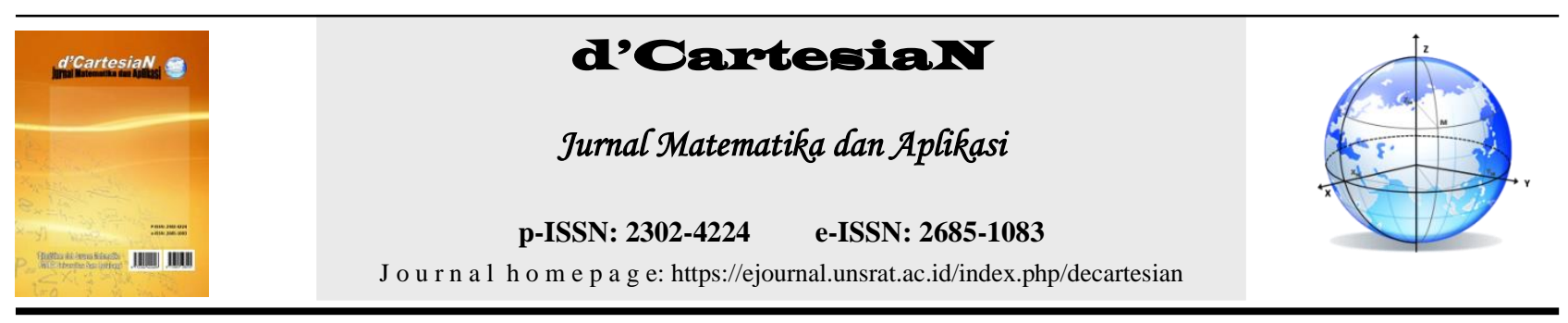

\title{
Penerapan Analisis Multidimensional Scaling dalam Pemilihan Jalur Destinasi Wisata di Kabupaten Bolaang Mongondow Area Kecamatan Lolak dan Sekitarnya
}

\author{
Febrina D. Simatupang1, Hanny A. H. Komalig1 ${ }^{*}$, Tohap Manurung1
}

${ }^{1}$ Jurusan Matematika-Fakultas Matematika dan Ilmu Pengetahuan Alam-Universitas Sam Ratulangi Manado,Indonesia

*Corressponding author : hanoyo7@yahoo.com

\begin{abstract}
A B S T R A K
Tujuan dari penelitian ini adalah untuk mendapatkan plot multivariate keberadaan lokasi wisata dan jalur wisata yang efektif dalam hal waktu dan jarak tempuh berdasarkan kedekatan antar lokasi wisata tesebut di Kabupaten Bolaang Mongondow area Kecamatan Lolak dan sekitarnya. Data yang digunakan dalam penelitian ini adalah data primer yang diperoleh dari Google Maps berdasarkan waktu dan jarak tempuh antar lokasi wisata di Kecamatan Lolak dan sekitarnya menggunakan transportasi roda empat. Metode yang digunakan adalah Metode Multidimensional Scaling. Dengan menggunakan metode ini, hasil yang diperoleh dari 15 lokasi wisata di Kecamatan Lolak dan sekitarnya dapat dikelompokkan menjadi 4 kelompok berdasarkan kedekatan antar lokasi-lokasi tersebut dengan melihat dua rute perjalanan yaitu Manado yang diwakili Kelurahan Inobonto dan Gorontalo yang diwakili Kecamatan Sangkub. Kelompok pertama: Pantai Pasir Besi, Pantai Tombolango, Pantai Losari, Pantai Bungin dan Pulau Molosing. Kelompok kedua: Hutan Bakau, Pantai Tanjung dan Bendungan Lolak. Kelompok ketiga: Air Terjun Sauk, Air Terjun Baturapa dan Pantai Beau. Kelompok keempat: Pantai Babo, Pantai Indah Maelang, Pantai Pasir Putih dan Pulau Tiga.
\end{abstract}

\section{INFO ARTIKEL:}

Diterima : 12 Juli 2020

Diterima setelah revisi : 29 Agustus 2020

Tersedia online : 6 Januari 2021

\section{Kata Kunci:}

Multidimensional Scaling

Plot Multivariat

Kecamatan Lolak

\begin{abstract}
A B S T RACT
The purpose of this study was to obtain a multivariate plot for the existence of tourist sites and effective tourist routes in terms of time and distance based on the proximity between these tourist sites in Bolaang Mongondow Regency, Lolak District and its surroundings. The data used in this study are primary data obtained from Google Maps based on the time and distance between tourist sites in Lolak District and its surroundings using four-wheeled transportation. The method used is the Multidimensional Scaling Method. By using this method, the results obtained from 15 tourist locations in Lolak District and its surroundings can be grouped into 4 groups based on the proximity between these locations by looking at two travel routes, namely Manado represented by Inobonto Village and Gorontalo represented by Sangkub District. The first group: Pasir Besi Beach, Buttonango Beach, Losari Beach, Bungin Beach and Molosing Island. Second group: Mangrove Forest, Tanjung Beach and Lolak Dam. Third group: Sauk Waterfall, Baturapa Waterfall and Beau Beach. The fourth group: Babo Beach, Pantai Indah Maelang, White Sand Beach and Pulau Tiga.
\end{abstract}

\section{ARTICLE INFO:}

Received : 12 July 2020

Received after revision : 29 August 2020

Available online : 6 January 2021

\section{Keywords:}

Multidimensional Scaling

Multivariate plot

Lolak district

\section{PENDAHULUAN}

Pariwisata merupakan salah satu aset penting dalam menunjang perkembangan ekonomi di suatu daerah. Melalui pariwisata, wisatawan dalam maupun luar negeri dapat mengetahui potensi dan keindahan dari daerah tersebut. Kabupaten Bolaang Mongondow tepatnya di Kecamatan Lolak dan sekitarnya, merupakan daerah yang memiliki potensi tinggi untuk menjadi pusat pariwisata. Kecamatan Lolak memiliki objek-objek wisata menarik yang masyarakat tidak banyak ketahui sehingga diperlukan observasi dan penelusuran agar potensi pariwisata di lokasi tersebut dapat lebih dikenal oleh wisatawan dalam maupun luar negeri. Dalam menentukan tujuan wisata, seringkali ada beberapa kendala yang timbul. Salah satunya dalam menentukan rute tercepat untuk menuju lokasi-lokasi wisata yang ingin dituju. Oleh karena itu perlu dilakukan suatu pengoptimalan dalam menentukan rute-rute perjananan yang efektif dalam hal waktu dan jarak tempuh untuk menuju objek-objek wisata yang tersebar di Kecamatan Lolak dan sekitarnya.

Dalam mengoptimasi atau memilih rute yang efektif dalam hal waktu dan jarak tempuh sebagai jalur destinasi wisata, perlu dilakukan suatu analisis untuk merepresentasikan kedekatan antar objek dalam hal ini lokasi-lokasi wisata di Kecamatan Lolak dan sekitarnya dalam bentuk plot multivariat. Multidimensional Scaling (MDS) atau Penskalaan Multidimensi merupakan suatu analisis yang dapat digunakan untuk memetakan atau mencari konfigurasi dari sejumlah objek dalam ruang berdimensi rendah berdasarkan ukuran jarak yang diharapkan dapat merefleksikan sebaik mungkin ukuran ketakmiripan antar objek tersebut. 


\section{Penerapan Analisis Multidimensional Scaling dalam Pemilihan Jalur Destinasi Wisata di Kabupaten Bolaang Mongondow Area Kecamatan Lolak dan Sekitarnya \\ d'Cartesian: Jurnal Matematika dan Aplikasi, Vol. 9, No. 2 (September 2020): 164-167}

Berdasarkan hasil plot yang didapat menggunakan metode Multidimensional Scaling, kelak akan diketahui jalur transportasi atau lintasan yang harus dilalui untuk mengefektifkan perjalanan menuju lokasi-lokasi wisata yang tersebar di Kecamatan Lolak dan sekitarnya berdasarkan dua titik awal dari arah yang berbeda.

\section{TINJAUAN PUSTAKA}

\subsection{Analisis Multidimensional Scaling}

Analisis multidimensional scaling (MDS) merupakan salah satu teknik peubah ganda yang dapat digunakan untuk menentukan posisi suatu objek berdasarkan penilaian kemiripannya. MDS berhubungan dengan pembuatan map untuk menggambarkan posisi sebuah objek dengan objek lainnya berdasarkan kemiripan objek-objek tersebut (Jawoiska, 2009).

\subsection{Multidimensional Scaling Metrik}

Data jarak yang digunakan dalam Penskalaan Berdimensi Ganda metrik adalah data rasio. Penskalaan Berdimensi Ganda metrik digunakan untuk menemukan himpunan titik dalam ruang dimensi $n$ dimana masing-masing titik mewakili satu objek sehingga jarak antar titik adalah $d_{r t} \approx f\left(\delta_{r t}\right)$. dimana $f$ adalah fungsi monotonic parametric kontinu. Fungsi ini dapat berupa fungsi identitas maupun fungsi transformasi ketakmiripan menjadi bentuk jarak (Mattjik, 2011).

\subsection{Multidimensional Scaling Non-Metrik}

Data jarak yang digunakan dalam Penskalaan Berdimensi Ganda non metrik adalah data yang dianggap bertipe ordinal. Untuk Penskalaan Berdimensi Ganda non metrik, fungsi transformasi hanya mempunyai batasan $\delta_{r t}<\delta_{r^{\prime} t^{\prime}} \Rightarrow f\left(\delta_{r t}\right) \leq$ $f\left(\delta_{r^{\prime} t^{\prime}}\right)$ untuk semua $1 \leq r, t, r^{\prime}, t^{\prime} \leq n$ (Mattjik, 2011).

\section{METODE PENELITIAN}

\subsection{Jenis dan Sumber Data}

Data yang digunakan dalam penelitian ini adalah data primer. Adapun data yang diperoleh berupa data jarak (lintasan) dan waktu tempuh antar lokasi-lokasi wisata di Kecamatan Lolak dan sekitarnya berdasarkan pengukuran Google Maps dalam satuan kilometer (KM) dan menit dengan menggunakan jalur rute roda empat.

\subsection{Waktu dan Tempat Penelitian}

Penelitian ini dilaksanakan selama bulan November 2019 sampai Februari 2020, mulai dari penyusunan proposal, pengambilan data serta pengolahan data. Pengolahan data dilakukan di Kabupaten Bolaang Mongondow dan Laboratorium Statistika, Fakultas Matematika dan Ilmu Pengetahuan Alam, Universitas Sam Ratulangi Manado.

\subsection{Variabel Penelitian}

Variabel yang digunakan adalah jarak (lintasan) dan waktu tempuh antar lokasi wisata di area Kecamatan Lolak dan sekitarnya dalam satuan kilometer dan menit.

\subsection{Analisis Data}

Metode yang digunakan dalam penelitian ini adalah Analisis Multidimensional Scaling. Sumber referensi yang digunakan berasal dari buku, jurnal ilmiah, dan artikel di internet.

Langkah-langkah:

1. Menentukan lokasi-lokasi wisata di kecamatan Lolak dan sekitarnya.

2. Menentukan titik koordinat lokasi wisata di Kecamatan Lolak dan sekitarnya yang akan dianalisa dalam aplikasi Google Maps.

3. Membuat matriks jarak berdasarkan data yang diperoleh berdasarkan jarak dan waktu tempuh.

4. Mengolah data berdasarkan analisis Multidimensional Scaling dengan menggunakan program analisis statistik komputer.

5. Mendapatkan rute optimal jalur destinasi wisata yang efektif di Kabupaten Bolaang Mongondow area Kecamatan Lolak dan sekitarnya.

\section{HASIL DAN PEMBAHASAN}

\subsection{Hasil Pengukuran Jarak Berdasarkan Google Maps}

Dua tabel dibawah ini adalah hasil pengukuran jarak antar lokasi-lokasi wisata di Kecamatan Lolak dan sekitarnya beserta titik acuan yang mewakili rute perjalanan dari Manado dan Gorontalo yaitu Kelurahan Inobonto dan Kecamatan Sangkub yang diperoleh dari Google Maps dalam satuan kilometer dan menit. Data tersebut diambil pada pagi menjelang siang hari berdasarkan jam rata-rata dalam keefektifan berwisata.

Tabel 1. Jarak Tempuh antar Lokasi Wisata di Kecamatan Lolak

\begin{tabular}{|c|c|c|c|c|c|c|c|c|c|c|c|c|c|c|c|c|c|c|}
\hline & & & & & & & $\mathrm{KA}$ & I W & SAT & & & & & & & & & \\
\hline & & 1 & 2 & 3 & 4 & 5 & 6 & 7 & 8 & 9 & 10 & 11 & 12 & 13 & 14 & 15 & ${ }^{*} \mathrm{~A}$ & ${ }^{*} \mathrm{~B}$ \\
\hline & 1 & 0 & 12 & 15 & 13 & 13 & 12 & 17 & 0.02 & 12 & 13 & 16 & 24 & 24 & 24 & 4.6 & 51 & 30 \\
\hline & 2 & 12 & 0 & 20 & 19 & 19 & 17 & 22 & 12 & 0.25 & 18 & 28 & 37 & 37 & 36 & 17 & 63 & 35 \\
\hline & 3 & 15 & 20 & 0 & 22 & 22 & 21 & 25 & 15 & 20 & 21 & 31 & 40 & 40 & 40 & 20 & 66 & 35 \\
\hline & 4 & 13 & 18 & 22 & 0 & 0 & 2.5 & 9.8 & 13 & 18 & 5.4 & 29 & 38 & 38 & 38 & 18 & 64 & 23 \\
\hline & 5 & 13 & 18 & 22 & 0 & 0 & 2.5 & 9.8 & 13 & 18 & 5.4 & 29 & 38 & 38 & 38 & 18 & 64 & 23 \\
\hline ४ & 6 & 13 & $\begin{array}{l}18 \\
\end{array}$ & 21 & 2.5 & 2.5 & 0 & 7.4 & 13 & 18 & 3 & 29 & 37 & 37 & 37 & 17 & 63 & 21 \\
\hline 5 & 7 & 17 & 22 & 25 & 9.8 & 9.8 & 7.4 & 0 & 17 & 22 & 5.4 & 33 & 41 & 41 & 41 & 21 & 68 & 19 \\
\hline 7 & 8 & 0.02 & 12 & 15 & 13 & 13 & 12 & 17 & 0 & 12 & 13 & 16 & 24 & 24 & 24 & 4.6 & 51 & 30 \\
\hline$\$$ & 9 & 12 & 0.25 & 20 & 18 & 18 & 17 & 22 & 12 & 0 & 20 & 28 & 37 & 37 & 36 & 17 & 63 & 35 \\
\hline 잉 & 10 & 13 & 18 & 21 & 5.8 & 5.8 & 3.4 & 4.8 & 13 & 20 & 0 & 29 & 37 & 37 & 37 & 18 & 63 & 21 \\
\hline & 11 & 16 & 28 & 31 & 29 & 29 & 28 & 33 & 16 & 28 & 31 & 0 & 8.4 & 8.4 & 8.3 & 11 & 35 & 46 \\
\hline & 12 & 24 & 37 & 40 & 38 & 38 & 37 & 41 & 24 & 37 & 40 & 8.4 & 0 & 0 & 1.8 & 20 & 27 & 55 \\
\hline & $\begin{array}{ll}13 \\
\end{array}$ & 24 & 37 & 40 & 38 & 38 & 37 & 41 & 24 & 37 & 40 & 8.4 & 0 & 0 & 1.8 & 20 & 27 & 55 \\
\hline & 14 & 23 & 35 & 38 & 36 & 36 & 35 & 40 & 23 & 35 & 35 & 6.9 & 5.6 & 5.6 & 0 & 18 & 29 & 54 \\
\hline & 15 & 4.6 & 17 & 20 & 18 & 18 & 17 & 21 & 4.6 & 17 & 17 & 11 & 20 & 20 & 20 & 0 & 46 & 35 \\
\hline & ${ }^{*} \mathrm{~A}$ & 51 & 63 & 66 & 64 & 64 & 63 & 68 & 51 & 63 & 63 & 35 & 27 & 27 & 29 & 46 & 0 & 81 \\
\hline & ${ }^{\prime} \mathrm{B}$ & 30 & 35 & 35 & 23 & 23 & 21 & 19 & 30 & 35 & 21 & 46 & 55 & 55 & 54 & 35 & 81 & 0 \\
\hline
\end{tabular}


Febrina D. Simatupang, Hanny A.H. Komalig, Tohap Manurung

d'Cartesian: Jurnal Matematika dan Aplikasi, Vol. 9, No. 2 (September 2020): 164-167

Tabel 2. Waktu Tempuh antar Lokasi Wisata di Kecamatan Lolak

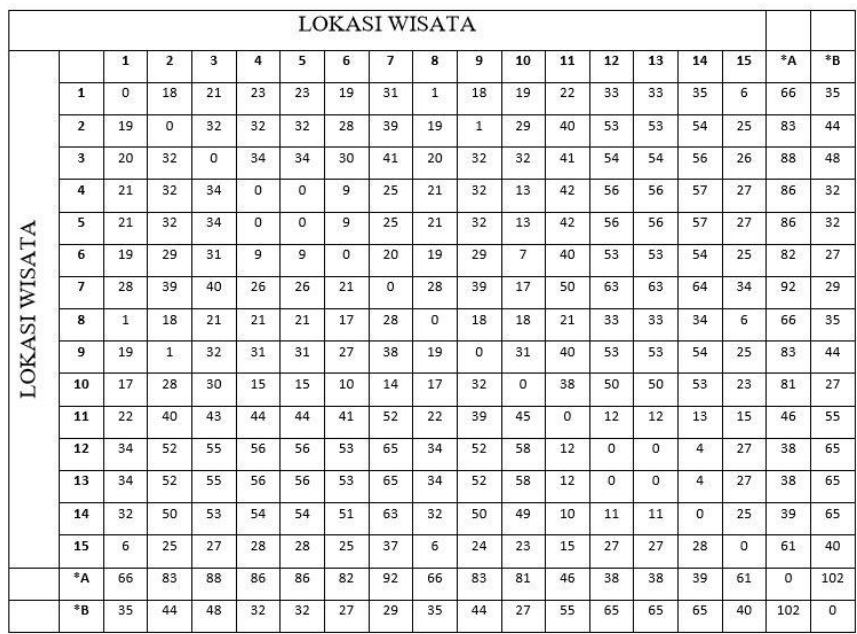

Keterangan:

1. Air Terjun Sauk

2. Hutan Bakau

10. Pantai Tombolango

3. Bendungan Lolak

4. Pantai Bungin

5. Pulau Molosing

6. Pantai Losari

7. Pantai Pasir Besi

8. Air Terjun Baturapa

9. Pantai Tanjung

\subsection{Hasil Pemetaan Multidimensional Scaling}

Berdasarkan output plot multivariat yang telah diperoleh menggunakan program analisis statistik, baik dalam data jarak maupun waktu, keduanya memiliki persamaan yang signifikan. Dapat dilihat pada gambar (1) dan (2) terdapat empat kelompok lokasi wisata yang dapat dilalui berdasarkan kedekatan antar lokasi wisata tersebut. Posisi titik yang terdapat pada output didasari oleh jarak antar variabel-variabel baik dalam satuan kilometer maupun menit. Terlihat jelas pula rute perjalanan dari arah Manado dan Gorontalo dalam hal ini diwakili oleh Kelurahan Inobonto dan Kecamatan Sangkub sebagai titik acuan untuk melihat urutan lintasan yang harus dilalui wisatawan yang akan melakukan perjalanan wisata di Kecamatan Lolak dan sekitarnya.

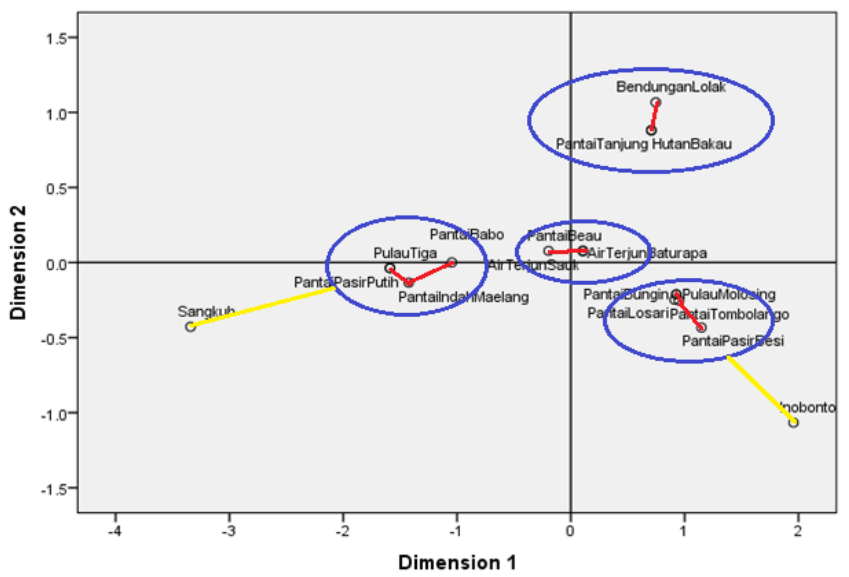

Gambar 1. Plot Multivariat lokasi wisata di Kecamatan Lolak berdasarkan jarak (KM)

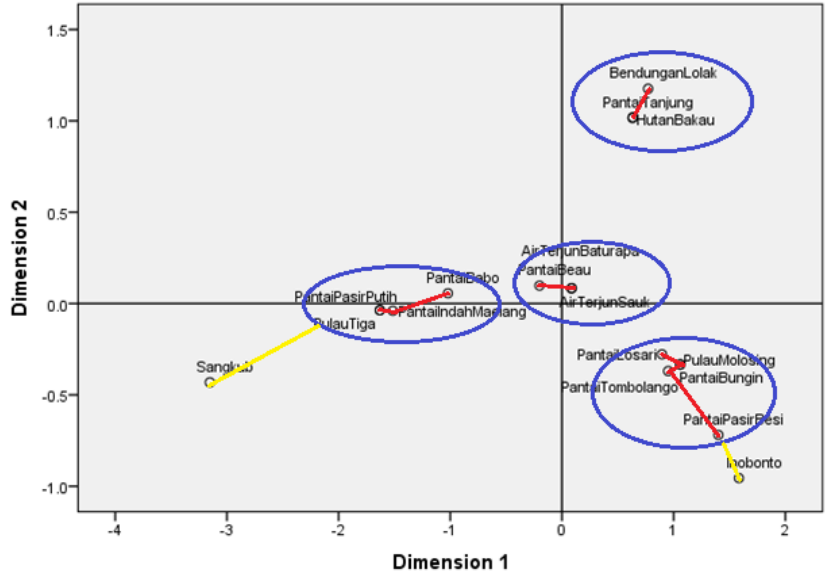

Gambar 2. Plot Multivariat lokasi wisata di Kecamatan Lolak berdasarkan waktu (menit)

\subsection{Interpretasi Jalur}

Klasifikasi jalur lokasi wisata di Kecamatan Lolak dan sekitarnya diambil berdasarkan tujuan dari metode Multidimensional Scaling. Adapun jalur yang ditentukan merupakan hasil interpretasi berdasarkan kedekatan antar objek-objek tersebut. Dalam menginterpretasikan jalur, agar perjalanan wisata terbilang efektif dalam hal waktu dan jarak tempuh, maka dibuat suatu pengelompokan berdasarkan kedekatan antar objek sehingga rute wisata yang akan dilalui sebagai prioritas adalah lokasi-lokasi wisata yang saling berdekatan satu dengan yang lain, sehingga dalam menentukan rute perjalanan dari arah Manado dan Gorontalo yang diwakili Kelurahan Inobonto dan Kecamatan Sangkub dapat terlihat lokasi-lokasi mana saja yang dapat dijadikan prioritas untuk dijadikan destinasi wisata.

Berdasarkan titik acuan Kelurahan Inobonto, kelompok pertama yang dapat dilalui antara lain berturut-turut,

\begin{tabular}{|c|c|}
\hline $\begin{array}{c}\mathbf{1} \\
\text { Pantai Pasir Besi } \\
\text { Pantai Tombolango } \\
\text { Pantai Losari } \\
\text { Pantai Bungin } \\
\text { Pulau Molosing }\end{array}$ & $\begin{array}{c}2 \\
\text { Hutan Bakau } \\
\text { Pantai Tanjung } \\
\text { Bendungan Lolak }\end{array}$ \\
\hline $\begin{array}{c}\mathbf{3} \\
\text { Air Terjun Sauk } \\
\begin{array}{c}\text { Air Terjun Baturapa } \\
\text { Pantai Beau }\end{array}\end{array}$ & $\begin{array}{c}4 \\
\text { Pantai Babo } \\
\text { Pantai Indah Maelang } \\
\text { Pantai Pasir Putih } \\
\text { Pulau Tiga }\end{array}$ \\
\hline
\end{tabular}

Sedangkan dari titik acuan Kecamatan Sangkub kelompok yang dilewati adalah sebaliknya.

Perlu digarisbawahi bahwa terdapat batasan dalam menentukan jalur destinasi wisata menggunakan metode ini. Dalam interpretasinya, plot multivariat 


\section{Penerapan Analisis Multidimensional Scaling dalam Pemilihan Jalur Destinasi Wisata di Kabupaten Bolaang Mongondow Area Kecamatan Lolak dan Sekitarnya \\ d'Cartesian: Jurnal Matematika dan Aplikasi, Vol. 9, No. 2 (September 2020): 164-167}

tersebut hanya melihat kedekatan antar objek sehingga dalam prakteknya, dibuat suatu asumsi dimana kelompok yang terdekat satu dengan yang lain merupakan urutan jalur atau lintasan yang dapat dilalui oleh wisatawan dalam mengunjungi destinasi wisata di Kecamatan Lolak dan sekitarnya, sehingga dalam penentuan jalur atau lintasan yang akan dilalui sifatnya adalah opsional dan fleksibel bagi wisatawan karena lintasan yang telah diolah menggunakan aplikasi hanya menunjukkan kedekatan antar lokasi wisata tersebut. Dan dari metode ini wisatawan dapat terbantu untuk bisa mengefektifkan waktu dan jarak tempuh dalam memilih jalur wisata di Kecamatan Lolak dan sekitarnya dengan melihat kedekatan antar objek-objek wisata tersebut.

\section{PENUTUP}

\subsection{Kesimpulan}

Berdasarkan analisis Multidimensional Scaling, dapat dilihat plot multivariate yang dihasilkan dari data jarak dan waktu tempuh antar lokasi wisata di Kecamatan Lolak dan sekitarnya menghasilkan beberapa kelompok yang ditentukan berdasarkan kedekatan antar lokasi-lokasi wisata tersebut sehingga memudahkan wisatawan untuk berkunjung secara efektif dari satu lokasi wisata ke lokasi wisata lainnya. Untuk titik acuan Kelurahan Inobonto Kelompok yang dilewati secara berturut-turut diantaranya, kelompok pertama: Pantai Pasir Besi, Pantai Tombolango, Pantai Losari, Pantai Bungin dan Pulau Molosing. Kelompok kedua: Hutan Bakau, Pantai Tanjung dan Bendungan Lolak. Kelompok ketiga: Air Terjun Sauk, Air Terjun Baturapa dan Pantai Beau. Kelompok keempat: Pantai Babo, Pantai Indah Maelang, Pantai Pasir Putih dan Pulau Tiga. Sedangkan dari titik acuan Kecamatan Sangkub kelompok yang dilewati adalah sebaliknya.

\subsection{Saran}

- Diharapkan penelitian ini dapat diterapkan di Kabupaten Bolaang Mongondow terlebih khusus area Kecamatan Lolak dan sekitarnya untuk kemajuan dalam sektor pariwisata melalui publikasi lewat internet.

- Dilakukan pemeliharaan terhadap lokasi-lokasi wisata yang ada untuk lebih menarik minat wisatawan agar dapat berkunjung di Kabupaten Bolaang Mongondow terlebih khusus are Kecamatan Lolak dan sekitarnya.

\section{REFERENSI}

[1] Jawoiska, N. 2009. A Review of Multidimentional Scaling (MDS) and its Utility in Various Psychological Domains. Journal Tutorials in Quantitative Methods for Psychology.(5)1: 1-10.

[2] Mattjik dan Sumertajaya. 2011. Sidik Peubah Ganda dengan Menggunakan SAS. Bogor: IPB Press.

[3] Pura, Komalig, dan Nainggolan. 2019. Analisis Multidimensional Scaling untuk Jarak Antara Fakultas-Fakultas serta Program Pasca Sarjana di Universitas Sam Ratulangi Manado. d'Cartesian: Jurnal matematika dan aplikasi. (8)1: 65-68.
[4] Wijaya, T. 2010. Analisis Multivariat. Yogyakarta: Universitas Ahmad Jaya Yogyakarta.

[5] https://bolmongkab.go.id/kecamatan pada 28 September 2019].

[Diakses

Febrina D. Simatupang (febrinasimatupang@gmail.com)

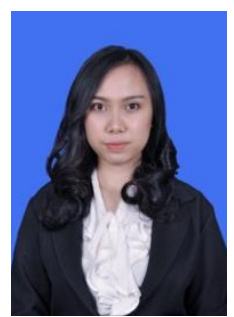

Lahir di Semarang, Jawa Tengah pada tanggal 12 Mei 1998. Menempuh pendidikan tinggi Jurusan Matematika, FMIPA, Universitas Sam Ratulangi Manado. Tahun 2019 adalah tahun terakhir ia menempuh studi. Makalah ini merupakan hasil penelitian skripsinya yang dipublikasikan.

Hanny A. H. Komalig (hanoyo7@yahoo.com)

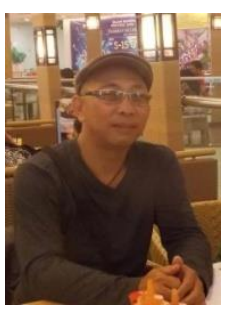
Lahir pada tanggal 6 Maret 1968. Pada tahun 1991 mendapatkan gelar Sarjana yang diperoleh dari Universitas Sam Ratulangi Manado. Gelar Magister Sains (M.Si) diperoleh dari Institut Pertanian Bogor pada tahun 1999. Ia bekerja di UNSRAT di Program Studi Matematika sebagai pengajar akademik tetap di UNSRAT.

Tohap Manurung (tohapm@unsrat.ac.id)

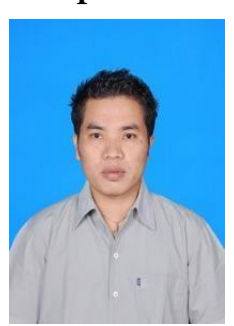

Lahir pada tanggal 24 Desember 1979. Pada tahun 2003 mendapatkan gelar Sarjana Sains (S.Si) yang diperoleh dari Universitas Sumatera Utara. Gelar Magister Sains (M.Si) diperoleh dari Institut Teknologi Bandung pada tahun 2010. Ia bekerja di UNSRAT di Program Studi Matematika sebagai pengajar akademik tetap UNSRAT. 